\title{
ABSTRACT OF SELECTED PAPER
}

Cancer of the Bladder in Spinal Cord Injury Patients by B. H. Broecker, F. A. Klein \& R. H. Hackler. The fournal of Urology, (198I), 125: 196-197.

This paper presents the observations made on I052 new admissions to the Spinal Cord Injury Centre at the McGuire Veterans Administration Medical Centre, Richmond, Virginia, U.S.A.

The authors provide support to the impression that the incidence of bladder cancer may be unusually high in patients with spinal cord injuries. This particularly applies to those with chronic infections or having had prolonged periods of bladder drainage by indwelling urethral catheter. Significant haematuria in long term paraplegic patients needs a complete bladder evaluation including a cystoscopy.

A. G. HARDY 